\title{
IMPLEMENTASI BLENDED LEARNING UNTUK MENINGKATKAN KEMANDIRIAN BELAJAR MAHASISWA
}

\author{
Dessy Rizki Suryani \\ Jurusan Pendidikan Matematika, Fakultas Keguruan dan Ilmu Pendidikan, Universitas Musamus \\ Jalan Kamizaun Mopah Lama, Merauke, Papua, Indonesia \\ e-mail: suryani_fkip@unmus.ac.id; \\ Revised: January 8, 2022 \\ Accepted: January 14, 2022
}

corresponding author*

\begin{abstract}
Abstrak
Tujuan dilaksanakannya penelitian ini adalah mengetahui peningkatan kemandirian belajar mahasiswa melalui implementasi blended learning. Subjek dalam penelitian ini adalah mahasiswa Jurusan Pendidikan Matematika Universitas Musamus yang mengambil mata kuliah persamaan diferensial sebanyak 32 mahasiswa. Penelitian tindakan kelas ini menggunakan siklus penelitian tindakan kelas Kemmis \& Mc Taggart yang dilakukan sebanyak 2 siklus. Teknik pengumpulan data yang digunakan berupa dokumentasi, observasi, dan wawancara. Dokumentasi yang digunakan adalah daftar nilai tugas dan nilai ujian tengah semester, untuk mengukur tingkat kemandirian belajar mahasiswa digunakan lembar observasi kemandirian belajar, serta untuk mengetahui respon mahasiswa terhadap pelaksanaan pembelajaran digunakan metode wawancara. Berdasarkan analisis data yang diperoleh, implementasi blended learning mampu meningkatkan kemandirian mahasiswa terbukti dari hasil yang diperoleh terjadi peningkatan jumlah mahasiswa yang memiliki kemandirian belajar. Data kemandirian belajar pra siklus menunjukkan bahwa sebesar 21,35\% mahasiswa memiliki aspek kemandirian belajar, setelah implementasi blended learning didapat hasil pada siklus 1 meningkat menjadi 49,38\% mahasiswa, dan mengkat lagi pada siklus 2 menjadi 78,75\% mahasiswa. Dengan implementasi blended learning juga mampu meningkatkan prestasi belajar mahasiswa yang ditunjukan dari data prestasi mahasiswa. Pada siklus 1, jumlah mahasiswa yang lulus sebesar 46,88\%, dan meningkat pada implementasi siklus 2 menjadi 71,88\%.
\end{abstract}

Kata Kunci: blended learning, kemandirian belajar

\section{IMPLEMENTATION OF BLENDED LEARNING TO IMPROVE STUDENT'S LEARNING INDEPENDENCE}

\begin{abstract}
The purpose of this research is to know the improvement of student learning independence through the implementation of blended learning. The subject in this study were students of the Department of Mathematics Education, Musamus University, who took the differential equations course as many as 32 students. This classroom action research uses a Kemmis \& Mc Taggart class action research cycle which is carried out in 2 cycles. Data collection techniques used in the form of documentation, observation and interviews. The documentation used are list of grades task and midterm exams, to measure student learning independence used learning independence observation sheet, as well as to determine student responses to implementation of learning using the interview method. Based on the analysis of the data obtained, the implementation of blended learning is able to increase student independence as evidenced by the results obtained there is an increase in the number of students who have learning independence. Pre-cycle learning independence data showed that $21.35 \%$ of students had aspects of learning independence, after the implementation of blended learning, the results in cycle 1 increased to $49.38 \%$ of students, and increased again in cycle 2 to $78.75 \%$ of students. With the implementation of blended learning, it is also able to improve student achievement as indicated by student achievement data. In cycle 1, the number of students who graduated was $46.88 \%$, and increased in the implementation of cycle 2 to $71.88 \%$.
\end{abstract}

Keywords: blended learning, independence learning

Copyright (C) Authors. This is an open access article distributed under the Attribution-NonCommercialShareAlike 4.0 International (CC BY-NC-SA 4.0), which permits unrestricted use, distribution, and reproduction in any medium, provided the original work is properly cited. 


\section{Pendahuluan}

Perkembangan teknologi yang semakin pesat menjadikan proses belajar mengajar yang dilakukan menjadi lebih fleksibel. Dari yang biasanya dilakukan secara tatap muka langsung di dalam kelas, saat ini prosesnya dapat dilakukan dimana saja dan kapan saja. Diskusi dan tanya jawab tidak hanya berlangsung pada jam kuliah di dalam kelas saja, tetapi dapat juga berlangsung di luar jam kuliah yang tidak harus mempertemukan dosen dan mahasiswa secara langsung. Dalam hal ini, dibutuhkan kemandirian belajar agar proses perkuliahan menjadi lebih berkualitas dan efektif sehingga mahasiswa dapat mencapai tujuan belajar yang ingin dicapai (Ismaniati et al., 2015).

Kemandirian belajar mahasiswa diperlukan untuk memupuk rasa tanggung jawab terhadap dirinya terutama bagi mahasiswa calon guru pada Jurusan Pendidikan Matematika. Dengan kemandirian belajar yang dimiliki membuat mahasiswa mampu mengerjakan segala sesuatu dengan kemampuan yang dimiliki tanpa bergantung kepada orang lain. Kemandirian belajar menurut Schunk dan Zimmerma adalah proses belajar yang terjadi karena pengaruh dari pemikiran, perasaan, strategi dan perilaku diri sendiri yang berorientasi pada pencapaian tujuan (Ekayanti, 2017). Menurut Knowles, kemandirian belajar diartikan sebagai proses dimana seorang individu mampu mengambil inisiatif, memformulasikan tujuan, mengidentifikasi sumber belajar, memilih dan mengimplementasikan strategi belajar yang cocok, serta mengevaluasi hasil belajar (A. R. Sari, 2013). Dari defenisi para ahli di atas, maka kemandirian belajar dapat didefinisikan sebagai bentuk aktifitas belajar mandiri yang tidak bergantung kepada orang lain, memiliki rasa tanggung jawab untuk merencanakan, melaksanakan dan mengevaluasi usahanya yang berorientasi pada pencapaian tujuan hasil belajar.

Pada Jurusan Pendidikan Matematika Universitas Musamus, salah satu mata kuliahnya adalah Persamaan Diferensial yang berbobot 3 sks. Materi perkuliahan Persamaan Diferensial ini secara umum adalah metode dasar untuk menentukan solusi dari persamaan diferensial biasa, sistem persamaan diferensial dan transformasi Laplace. Berdasarkan hasil observasi dalam pelaksanaan perkuliahan dengan menggunakan lembar observasi kemandirian belajar, dapat dilihat bahwa kemandirian belajar mahasiswa masih rendah. Hal ini ditunjukkan dengan hasil pra siklus yang menunjukkan bahwa sebanyak $78,75 \%$ mahasiswa belum memiliki aspek kemandirian belajar. Metode pembelajaran yang digunakan pun masih konvensional, dan dosen masih belum memaksimalkan pemanfaatan internet dalam perkuliahan.

Sesuai masalah yang dipaparkan di atas, untuk mencapai kualitas belajar yang maksimal sehingga dapat meningkatkan kemandirian mahasiswa, maka dibutuhkan suatu metode pembelajaran yang tepat. Untuk meningkatkan kemandirian belajar mahasiswa, salah satu metode pembelajaran yang dapat digunakan adalah Blended learning (Ismaniati et al., 2015). Fitriasari (2018) menerapkan blended learning pada perkuliahan metode numerik. Hasil penelitian menunjukkan bahwa penggunaan blended learning berpotensi meningkatkan kemandirian belajar mahasiswa, mahasiswa dengan menggunakan blended learning memiliki peningkatan kemandirian belajar lebih besar dibandingkan mahasiswa dengan pembelajaran konvensional (Fitriasari et al., 2018). Oleh sebab itu, dalam penelitian tindakan kelas (PTK) ini akan digunakan metode blended learning.

Blended learning merupakan kegiatan pembelajaran yang mengombinasikan komponen terbaik dari pembelajaran online dengan pembelajaran tatap muka (Rahmi, 2018). Pada dasarnya, blended learning merupakan suatu metode pembelajaran yang mengombinasikan belajar tatap muka dengan belajar online menggunakan media internet (A. R. Sari, 2013). Blended learning mengharuskan mahasiswa lebih aktif dalam pembelajarannya, karena pembelajaran fokus utamanya adalah pembelajar. Penggunaan blended learning diharapkan dapat memperkuat metode pembelajaran konvensional di dalam kelas dengan bantuan teknologi.

Tujuan penggunaan blended learning adalah untuk membantu mahasiswa dalam memahami konsep sesuai dengan gaya belajar yang dimiliki, memberikan kesempatan kepada dosen dan mahasiswa untuk belajar mandiri, serta memberikan proses pembelajaran yang fleksibel (Nurhayati et al., 2021). Salah satu kelebihan blended learning adalah proses belajar bisa terjadi kapan saja dan dimana saja tanpa dibatasi ruang dan waktu. Blended learning juga mampu meningkatkan interaksi dalam pembelajaran antara komponen pembelajaran (M. Sari \& Asmendri, 2019). Dengan demikian, implementasi blended learning diharapkan mampu meningkatkan kemandirian belajar mahasiswa jurusan Pendidikan Matematika yang mengambil mata kuliah persamaan diferensial. Sehingga, tujuan dalam penelitian ini adalah untuk mengetahui peningkatan kemandirian belajar mahasiswa melalui implementasi blended learning. 


\section{Metode Penelitian}

Penelitian ini merupakan penelitian tindakan kelas (classroom action research) dengan desain penelitian spiral dari Kemmis \& Mc Taggart. Penelitian dilaksanakan selama lima bulan sejak September 2020 sampai Januari 2021 pada mata perkuliahan Persamaan Diferensial yang dilaksanakan di Jurusan Pendidikan Matematika Fakultas Keguruan dan Ilmu Pendidikan Universitas Musamus. Subjek dalam penelitian ini adalah mahasiswa yang mengambil mata kuliah Persamaan Diferensial sebanyak 32 mahasiswa. Siklus penelitian tindakan kelas menggunakan siklus Kemmis \& Mc Taggart yang dilakukan sebanyak 2 siklus dengan mengikuti tahapan berulang dalam setiap siklusnya. Tahapan penelitian yang digunakan yaitu planing, action, observation, dan reflection (Lestari \& Suryani, 2019).

Dalam penelitian ini menggunakan teknik pengumpulan data berupa dokumentasi, observasi, dan wawancara. Dokumentasi yang digunakan adalah nilai tugas dan nilai Ujian Tengah Semester (UTS) untuk melihat ketercapaian prestasi dari implementasi blended learning. Data yang dikumpulkan untuk mengetahui tingkat kemandirian belajar mahasiswa menggunakan lembar observasi kemandirian belajar mahasiswa yang diberikan pada prasiklus, akhir siklus 1 dan akhir siklus 2. Lembar observasi kemandirian belajar disusun berdasarkan indikator kemandirian belajar yang meliputi mengambil inisiatif, memformulasikan tujuan belajar, mengidentifikasi hasil belajar, memilih dan mengimplementasikan hasil belajar, serta mengevaluasi hasil belajar (A. R. Sari, 2013). Dengan menggunakan 5 indikator kemandirian ini maka aspek kemandirian mahasiswa dapat diukur. Untuk menilai jumlah mahasiswa yang mempunyai kemandirian belajar pada pra siklus, siklus 1 dan siklus 2, maka digunakanlah kelima indikator tersebut sebagai pedoman. Wawancara dilakukan kepada 3 mahasiswa dengan tingkat kemampuan yang berbeda untuk mengetahui respon dari pelaksanaan pembelajaran dengan menggunakan blended learning. Kriteria keberhasilan PTK dalam penelitian ini yaitu minimal $75 \%$ jumlah mahasiswa telah memiliki kemandirian belajar di setiap aspek indikator kemandirian.

\section{Hasil dan Pembahasan}

Implementasi blended learning ini menggunakan versi flipped classroom yang dimulai dengan pembelajaran secara online yang dilakukan di luar kelas kemudian dilanjutkan dengan pembelajaran tatap muka di kelas guna memperdalam materi yang telah diberikan dalam kelas online. Dalam kelas online media yang diberikan beragam, terdiri dari handout dan video, hal ini diharapkan dapat mengakomodir gaya belajar yang dimiliki oleh mahasiswa. Di dalam kelas online juga mahasiswa diberikan evaluasi berupa kuis untuk mengukur sejauh mana pemahaman mahasiswa dari materi yang diberikan.

Dalam implementasi blended learning yang dilakukan pada pelaksanaan mata kuliah persamaan diferensial ini, mahasiswa tidak mengalami kesulitan yang bermakna. Mahasiswa mampu mengikuti seluruh proses perkuliahan dengan baik. Hal ini dikarenakan mahasiswa sudah terbiasa dengan perkembangan teknologi saat ini. Dengan adanya tugas di setiap kelas online memaksakan mahasiswa untuk belajar secara mandiri agar dapat mengikuti kelas tatap muka. Materi yang diberikan pun bervariasi meliputi handout dan video pembelajaran sehingga mahasiswa lebih mudah untuk mengulang mempelajari materi kuliah secara mandiri.

Hasil analisis data kemandirian mahasiswa yang mengambil mata kuliah persamaan diferensial pada pra siklus, akhir siklus 1, dan akhir siklus 2 diperoleh data yang di tampilkan pada tabel 1 berikut. 
Tabel 1. Data Kemandirian Belajar Mahasiswa

\begin{tabular}{|c|c|c|c|c|c|c|c|}
\hline No & Indikator Kemandirian Belajar & \multicolumn{2}{|c|}{ Pra Siklus } & \multicolumn{2}{|c|}{ Siklus 1} & \multicolumn{2}{|c|}{ Siklus 2} \\
\hline 1 & $\begin{array}{l}\text { Mengambil inisiatif, baik dengan atau tanpa } \\
\text { bantuan orang lain untuk mendiagnosa } \\
\text { kebutuhan belajar }\end{array}$ & 8 & $25 \%$ & 17 & $53,13 \%$ & 26 & $81,25 \%$ \\
\hline 2 & Memformulasikan tujuan belajar & 7 & $21,88 \%$ & 15 & $46,88 \%$ & 25 & $78,13 \%$ \\
\hline 3 & Mengidentifikasi sumber belajar & 5 & $15,63 \%$ & 18 & $56,25 \%$ & 26 & $81,25 \%$ \\
\hline 4 & $\begin{array}{l}\text { Memilih dan mengimplementasikan strategi } \\
\text { belajar yang cocok untuk dirinya }\end{array}$ & 8 & $25 \%$ & 14 & $43,75 \%$ & 24 & $75 \%$ \\
\hline 5 & Mengevaluasi hasil belajar & 6 & $18,75 \%$ & 15 & $46,88 \%$ & 25 & $78,13 \%$ \\
\hline & Rata-rata & & $21,25 \%$ & & $49,38 \%$ & & $\mathbf{7 8 , 7 5 \%}$ \\
\hline
\end{tabular}

Data kemandirian belajar mahasiswa sebelum implementasi blended learning adalah sebanyak $21,25 \%$ mahasiswa yang memiliki aspek kemandirian belajar. Dapat dilihat bahwa setelah implementasi blended learning yang dilakukan dalam perkuliahan persamaan diferensial didapatkan hasil bahwa rata-rata siklus 1 meningkat menjadi $49,38 \%$ mahasiswa, dan meningkat lagi pada siklus 2 menjadi 78,75\% mahasiswa.

Berdasarkan indikator kemandirian belajar, pada siklus 2 sebanyak $81,25 \%$ mahasiswa mampu mengambil inisiatif untuk mendiagnosa kebutuhan belajarnya, $78,13 \%$ mahasiswa mampu memformulasikan tujuan belajarnya, $81,25 \%$ mahasiswa mampu mengidentifikasi sumber belajarnya, $75 \%$ mahasiswa mampu memilih dan menerapkan strategi belajar yang cocok untuk dirinya, dan $78,13 \%$ mahasiswa mampu mengevaluasi hasil belajarnya. Sehingga dapat disimpulkan bahwa terjadi peningkatan kemampuan mahasiswa sebelum dan sesudah implementasi blended learning. Untuk setiap item indikator juga telah memenuhi kriteria keberhasilan penelitian tindakan kelas. Maka penelitian dihentikan sampai siklus ke 2 .

Dalam perkuliahan tatap muka maya yang dilakukan secara online, memberikan kesempatan kepada mahasiswa secara mandiri untuk mencapai keberhasilan belajarnya. Materi yang diberikan secara online juga dapat dipelajari kembali kapan saja dan dimana saja, sehingga mahasiswa yang mengatur sendiri kapan harus memulai dan menyelesaikan proses belajarnya. Jika saat mengulang materi masih ada hal yang belum dipahami, maka mahasiswa dapat menghubungi dosen melalui email, ataupun dalam dialog interaktif yang disediakan pada waktu yang telah ditentukan bersama. Dengan demikian, implementasi blended learning mampu meningkatkan kemandirian belajar mahasiswa.

Implementasi blended learning juga mampu meningkatkan prestasi mahasiswa. Dalam pelaksanannya, banyaknya mahasiswa yang lulus semakin meningkat di setiap siklusnya. Peningkatan prestasi ini dapat dilihat pada tabel 2 berikut.

Tabel 2. Data Prestasi Mahasiswa

\begin{tabular}{lccccc}
\hline Penilaian & \multicolumn{3}{c}{ Mahasiswa Lulus } & $\begin{array}{c}\text { Mahasiswa Tidak } \\
\text { Lulus }\end{array}$ & $\begin{array}{c}\text { Total } \\
\text { Mahasiswa }\end{array}$ \\
\hline Nilai tugas siklus 1 & 15 & $46,88 \%$ & 17 & $53,13 \%$ & 32 \\
Nilai tugas siklus 2 & 23 & $71,88 \%$ & 9 & $28,13 \%$ & 32 \\
Nilai UTS & 29 & $90,63 \%$ & 3 & $9,38 \%$ & 32 \\
\hline
\end{tabular}

Berdasarkan analisis data yang pada tabel di atas, dapat dilihat bahwa implementasi blended learning juga mampu meningkatkan prestasi belajar mahasiswa. Pada siklus 1, jumlah mahasiswa yang lulus sebesar 46,88\%, dan meningkat pada implementasi siklus 2 menjadi $71,88 \%$.

Berdasarkan hasil wawancara yang dilakukan kepada 3 mahasiswa dengan tingkat kemampuan yang berbeda, diperoleh hasil bahwa mahasiswa merasa bahwa dengan implementasi blended learning ini mampu meningkatkan kemandirian belajar yang dimiliki mahasiswa. Proses pembelajaran yang tidak terikat oleh ruang dan waktu dengan menggunakan akses internet memudahkan mahasiswa untuk dapat belajar dimanapun dan kapanpun. Materi yang diberikan pada kelas online dapat dipelajari kembali sehingga mahasiswa lebih mudah untuk mengulang pembelajaran secara mandiri. Dengan 
adanya evaluasi yang diberikan pada kelas online memaksakan mahasiswa untuk dapat belajar secara mandiri sebelum masuk pada kelas tatap muka sehingga dengan sendirinya mampu membiasakan mahasiswa untuk mandiri dalam proses belajarnya.

Berdasarkan hasil data kemandirian, prestasi mahasiswa, dan hasil wawancara, maka implementasi blended learning mampu meningkatkan kemandirian belajar mahasiswa. Dengan implementasi blended learning ini dapat memberikan kesempatan bagi mahasiswa untuk lebih mandiri dalam pelaksanaan pembelajarannya yang tidak terikat ruang dan waktu. Mahasiswa mendapatkan pengalaman belajar baru yang tidak hanya dilakukan di dalam kelas. Mahasiswa juga dapat lebih memanfaatkan penggunaan gadget yang dimilikinya untuk proses pembelajaran. Sejalan dengan penelitian sebelumnya, bahwa penggunaan gadget berpengaruh terhadap kemandirian belajar mahasiswa (Suhartini et al., 2018). Sehingga, dengan menggabungkan pembelajaran tatap muka dan online tentunya sangat cocok bagi mahasiswa milenial,

\section{Kesimpulan}

Dari hasil dan pembahasan yang telah dipaparkan sebelumnya maka didapatkan kesimpulan bahwa kemandirian belajar mahasiswa Jurusan Pendidikan Matematika Universitas Musamus dapat ditingkatkan dengan implementasi model blended learning dalam pelaksanaan kuliah. Mahasiswa dapat mengikuti perkuliahan yang tidak monoton hanya terjadi di dalam kelas dengan menggunakan model konvensional. Implementasi blended learning mampu membuat mahasiswa dengan sendirinya mengasah kemandirian belajar yang dimilikinya sebagai modal untuk menjadi seorang guru.

Mahasiswa saat ini lebih tertarik dengan dunia digital menggunakan gadget yang dimilikinya dan belajar dengan menggunakan akses internet. Kemandirian dalam belajar tidak berarti bahwa mahasiswa belajar secara mandiri tanpa bantuan dosen, sehingga dosen sebagai fasilitator diharapkan mampu memberikan fasilitas yang memadai dan tepat agar dapat meningkatkan kemandirian belajar para mahasiswa. Salah satu hambatan dalam proses pembelajaran online adalah koneksi internet (Anhusadar, 2020). Maka, dukungan teknologi dan koneksi internet yang memadai pun turut mengambil peran penting dalam kelancaran implementasi model pembelajaran ini.

\section{Daftar Pustaka}

Anhusadar, L. (2020). Persepsi Mahasiswa PIAUD terhadap Kuliah Online di Masa Pandemi Covid 19. KINDERGARTEN: Journal of Islamic Early Childhood Education, 3(1), 44-58. https://doi.org/10.24014/kjiece.v3i1.9609

Ekayanti, R. (2017). Optimalisasi Aplikasi Edmodo dalam Meningkatkan Kemandirian Belajar dan Kesadaran Berbahasa Mahasiswa pada Mata Kuliah Literary Criticism Di FKIP UMSU. Jurnal EduTech, 3(1), 148-165.

Fitriasari, P., Tanzimah, \& Sari, N. (2018). Kemandirian Belajar Mahasiswa Melalui Blended Learning Pada Mata Kuliah Metode Numerik. Jurnal Elemen, 4(1), 1-8. https://doi.org/10.32505/v3i2.1367

Ismaniati, C., Sungkono, \& Wahyuningsih, D. (2015). Model Blended Learning untuk Meningkatkan Kemandirian Belajar dan Daya Tarik dalam Perkuliahan. Jurnal Penelitian Ilmu Pendidikan, 8(2), 19-27.

Lestari, N., \& Suryani, D. R. (2019). Penggunaan Variasi Media Pembelajaran untuk Meningkatkan Motivasi dan Minat Belajar Matematika Siswa Kelas XI IPS 3 SMA Negeri 2 Merauke. Musamus Journal Of Mathematics Education, 1(2), 74-79.

Nurhayati, Suryani, D. R., \& Nur'aini, K. D. (2021). The Effect of Blended Learning on Students' amethematical Proving Ability. Proceedings of The International Joined Conference on Social Science (ICSS 2021), 603, 438-440. https://www.atlantispress.com/proceedings/icss-21/125965154

Rahmi, U. (2018). Desain Sistem Pembelajaran Blended Learning: Upaya Peningkatan Kualitas Pendidikan Di Indonesia. 122-137. https://doi.org/10.31227/osf.io/j84c3

Sari, A. R. (2013). Strategi Blended Learning Untuk Peningkatan Kemandirian Belajar Dan Kemampuan Critical Thinking Mahasiswa Di Era Digital. Jurnal Pendidikan Akuntansi Indonesia, 11(2), 32-43. https://doi.org/10.21831/jpai.v11i2.1689

Sari, M., \& Asmendri. (2019). Analisis Model-Model Blended Learning di Lembaga Pendidikan. NATURAL SCIENCE: Jurnal Pendidikan IPA Dan Pendidikan IPA, 5(2), 835-847.

Suhartini, A. S., Meirista, E., \& Nur'aini, K. D. (2018). Pengaruh Penggunaan Gadget Terhadap Kemandirian Mahasiswa Pendidikan Matematika Universitas Musamus. Musamus Journal of Mathematics Education, 1(1), 43-51. 